\title{
Welcome to the first open access issue of Theofilos
}

\section{Dear Readers!}

With many others, you may be reading this on a paper - still warm off the printer - or on a digital screen in some form or other. Indeed, most of you are probably not holding a physical copy of Theofilos in your hands as you are reading these words!

It is now a universal trend that academic as well as popular texts are increasingly being published on various digital platforms. The editorial board of Theofilos decided to join this trend, and from this issue onwards we begin digital publication. The transition to open access was led by our wise and patient Chief Editor, Lars Dahle, and has involved new and fascinating insights into the nature and ethics of academic publishing.

A consequence of all this hard work is that the publication dates are dramatically delayed in 2020. Still, in view of the attractive new format and the ongoing relevant content, we think it was worth waiting! Among other things, all articles (in due time also for back issues) now have their unique DOI-number. This is a fantastic search tool for academics, and this function was a strong motivator to begin the process towards open access publishing.

We are therefore proud and happy to be able to present Theofilos as a modern journal in the best sense of the word - being able to moderate its message in tune with the contemporary context and thereby reaching more readers than the limited paper edition was ever able to do.

I hasten to add that for those who would like to continue to read the paper edition and I am one of them! - it will be printed in a very limited edition and distributed to strategically chosen libraries in Scandinavia. See list on the homepage (www.theofilos.no). This is made possible with financial support from Pro Fide et Christanismo.

In the journey towards becoming an online journal, we have also examined the ethical guidelines of Theofilos, and we will continue to work towards ensuring a high quality in our editorial and peer review processes. Another important focus area in the near and far future is online marketing in various ways, so that news about upcoming issues and articles, and key related physical and digital events, will be made known more widely.

Let me also add that from the end of 2020 I will continue my work as co-editor for Theofilos as part of my role as Associate Professor in Systematic Theology at Johannelund School of Theology. Thus, the institutional partnership between NLA University College and Johannelund has been strengthened. I look forward to benefit from the collegia of both these fine institutions in our ongoing editorial work with Theofilos. Let me add that Lars' combination of enthusiasm and wisdom in Christ is important not only to the existence and development of Theofilos but to much more besides. I am grateful to continue to be his co-worker.

On behalf of both of us as Editors, I would also like to thank the infatigable Sune Jäderberg at Förlaget Boken who has been responsible for the production and layout of Theofilos since our humble beginnings in 2009. We appreciate his meticulous care for details and his great sense of humor. Kjetil Fyllingen, our excellent web consultant at Damaris Norge, established our new website in June 2019, and has now facilitated our transition to open access with a steady hand.

This first open access issue is a Supplement issue based on the Veritas Research Symposium at the NLA Gimlekollen Campus in Kristiansand, Norway, in October 


\section{Theofilos}

A Nordic open access journal in Theology, Philosophy and Culture

Published by NLA University College - in partnership with Johannelund School of Theology

Available at www.theofilos.no

2018. The theme is "Science, Natural Theology, and Christian Apologetics". It has been edited by our Chief Editor, our Book Editor Bjørn Hinderaker, and with Peter S. Williams as our Guest Editor. We are truly grateful for Pete's assistance in editing all the texts and for his own substantial contributions, and we also extend our thanks to all the other contributors. So, without further ado, I will let our Guest Editor introduce the exciting content of this first open access issue of Theofilos.

Tolle et lege!

Stefan Lindholm, Editor

Uppsala, Sweden, December 2020

\section{Introducing the Theofilos Supplement issue on Science, Natural Theology, and Christian Apologetics}

[In early 2018, I proposed an annual research 'symposium' to be held at the NLA Gimlekollen Campus (with academic presentations and discussion, but with coffee replacing the traditional Greek wine). I was delighted to see NLA colleagues run with the concept, such that the Veritas Research Symposium launched in October 2018 is now an annual event at the campus in Kristiansand, Norway. The symposium's focus is research on challenges, themes, and issues in Christian apologetics and related missiological, theological and philosophical areas. The symposium is closely linked to the annual Norwegian Veritas Conference. ${ }^{1}$

The theme chosen for the inaugural symposium was Science, Natural Theology, and Christian Apologetics. This is an exciting topic for interdisciplinary research of key relevance to contemporary culture. Once we had a view of the proposed papers, it became clear that they fell naturally into three sub-topics which we used to structure the Symposium: 'Issues in Genesis', 'Issues in Natural Theology' and 'Issues in Contemporary Popular Culture'.

Papers presented at the 2018 symposium were subsequently read and commented upon by the co-editors of this Supplement issue of Theofilos (Chief Editor Lars Dahle, Book Editor Bjørn Hinderaker and myself as Guest Editor), before being revised by the contributors and submitted to the standard double blind peer review process.

\section{The academia section}

The editorial and the peer review procedures resulted in seven academic articles from the Symposium. The articles cover the three topical areas mentioned above and represent a fascinating spectrum of positions and perspectives.

\section{Issues in Genesis}

- Jens Bruun Kofoed (Fjellhaug International University College):

'Approaching Genesis and science: Hermeneutical principles and a case study'

- Gunnar Innerdal (NLA University College, Bergen): 'The origin of sin - in dialogue with natural science'

\section{Issues in Natural Theology}

- Knut-Willy Saether (Volda University College): 'The apologetic fruitfulness of a revised natural theology'

- Atle Søvik (MF Norwegian School of Theology, Religion and Society, Oslo): 'How to formulate the fine-tuning argument for the existence of God?'

- Steinar Thorvaldsen (UiT, The Arctic University of Norway, Tromsø): 'Intelligent design and natural theology' 